\title{
Applying discursive approaches to health psychology
}

\begin{abstract}
Objective: The aim of this paper is to outline the contribution of two strands of discursive research, glossed as 'macro' and 'micro', to the field of health psychology. A further goal is to highlight some contemporary debates in methodology associated with the use of interview data versus more naturalistic data in qualitative health research.
\end{abstract}

Method: Discursive psychology is a way of analysing talk as a social practice which considers how descriptions are put together and what actions they achieve.

Results: A selection of recent examples of discursive research from one applied area of health psychology, studies of diet and obesity, are drawn upon in order to illustrate the specifics of both strands. Whilst both approaches focus on accountability, 'macro' discourse work is most useful for identifying the cultural context of talk and can demonstrate how individuals are positioned within such discourses, and examine how such discourses are negotiated and resisted. 'Micro' discursive research pays closer attention to the sequential organisation of constructions and focuses on naturalistic settings which allow for the inclusion of an analysis of the health professional.

Conclusion: Diets are typically depicted as an individual responsibility in mainstream health psychology but discursive research highlights how discourses are collectively produced and bound up with social practices.

Key words: Discursive research, application, health psychology 


\section{Introduction}

The 'turn to language' has been well documented and each discipline has its own distinctive concerns, definitions of discourse, theoretical positions and methodologies which may confuse those new to this type of research. Overall, however, the consequences of this burgeoning work has been to produce 'discourse analysis' as a broad "theory of language an communication, a perspective on social interaction and an approach to knowledge construction across history, societies and culture" (Wetherell et al, 2001, p.1). Discourse analysis stems from the shift in epistemology provided through critiques of 'essentialist' understandings of the world. Language is central to most research practices in health psychology from questionnaires and survey data collection to interviews and even to the ways in which findings are reported (Gilbert \& Mulkay, 1984). The turn to language brought with it an awareness of these structuring properties. A major shift in thinking was the move from the notion of language as a transparent medium used to convey pre-existing knowledge to a view of language as the site where we actually constitute knowledge. Discursive approaches treat language as action with the primary focus considering how health and illness are constructed, oriented to and displayed in social interactions. The aim of this paper is to introduce the novice discourse health researcher into the field by outlining the potential contribution of two strands of discursive research in psychology, glossed here as 'macro' and 'micro' approaches, in order to enhance the study of a wide `range of health and illness topics. The first 'macro stand' strand, referred to in this paper by the umbrella term of discourse analysis, encompasses critical discourse analysis (Fairclough, 1995), poststructuralist and Foucauldian approaches (Parker,1992), and critical discursive psychology (Edley, 2001) all employing a broader interpretive framework, typically using, though not limited to, interviews and focus groups as the means of data collection. The second 'micro' 
strand, referred to in this paper as discursive psychology (Edwards \& Potter, 1992) and more recently as the Loughborough School of social psychology (Stoke, Hepburn \& Antaki, 2012), is more heavily, and increasingly, influenced by insights from conversation analysis (Sacks, 1992) and favours a sequential analysis of naturalistic data. The first section of the paper will briefly outline tensions between these strands to highlight their differences and to show in subsequent sections how these might be used for different purposes in health psychology. Recent examples of studies of eating practices, diet and obesity are drawn upon to discuss both strands in order to demonstrate key differences, and overlaps in approaches. A further goal is to highlight some contemporary debates in methodology associated with the use of interview data versus more naturalistic data in qualitative health research. Focusing on data from the author's recent interview study about male obesity, these methodological issues are highlighted, and the usefulness of each outlined for health psychologists. Finally, the advantages of applying a discursive approach to health topics in general will be discussed.

\section{The divide between 'macro' and 'micro' approaches to discourse}

How different discourse researchers conceptualise the term 'discourse' varies on a continuum from a broad focus at one end, as in Foucault's (1978) historical analysis of developing social practices such as those associated with sexuality, to a fine grained conversation analytic focus on turn taking as in Sack's research on telephone calls to a Suicide prevention service (Sacks, 1992) at the other. Crudely speaking, those approaches that focus on 'macro' analyses refer to the way that topics, social practices, forms of subjectivity and power relations are constructed in particular historical periods (Weedon, 1987) and tend to be interested in how individuals are positioned by the identified patterns (Foucault, 1982). The traditional notion of the subject found in much health psychology 
research was constructed as a fully conscious, stable and independent being. For example, studies of eating practices, diet and obesity from a mainstream psychological perspective typically tend to treat the individual as a rational and autonomous being (Malson, 1998). In contrast to this, discursive and social constructionist research view identity as constituted and reconstituted through discourse and is thus flexible, contextual, relational, situated and inflected by power relations (Gergen, 19943). Davies and Harre (1990) argue that identity is always an open question witch shifts in relation to the positions made available through talk, in interaction and conversations. The story lines of everyday conversations provide us with a position to speak from and they allow the positioning of others as characters with roles and rights. Subject positions also open up possibilities for shifting resistances. 'Macro' approaches then often prioritise the examination of political implications of the patterns studied and make wider interpretations of the data based on the analyst's own cultural knowledge. In contrast to this, those who adopt a more fine-grained approach are less inclined to want to make such speculations, arguing that one should stick more closely to the text. These distinctions between discourse traditions are informed by different theoretical positions and methodological practices although boundaries between approaches are often blurred as discourse researchers borrow from different theoretical resources and synthesise new approaches, again hard to decipher for the novice discourse researcher. However, a key focus for all approaches continues to be on discourse in the form of talk and text with a major interest in "the ways in which discourse is oriented to actions within settings, the way representations are constructed and oriented to action, and a general caution about explanations of conduct based in the cognition of individuals" (Potter \& Wiggins, 2007, 74).

These differences between 'macro' and 'micro' approaches are reflected in a debate occurring in discourse studies between conversation analysis (Schegloff, 1997) on the 
one hand, and critical discourse analysis (Van Dijk, 1997) and post-structuralist influenced discourse analysis on the other (Wetherell, 1998, 2001). The debate in question stems from Schegloff's criticisms of what he terms 'critical approaches to discourse analysis' (see Schegloff 1997, 1998, 1999; see replies from Wetherell, 1998; Billig, 1999a, 1999b). Schegloff (1997) was concerned that discourse analysts were imposing their own frame of reference on the world that participants have constructed. Schegloff argued that analysts should not use terms which preoccupy them as a starting point for analysis as they have no "principled method for establishing those orientations" (Schegloff, 1997, 167). Instead, they should focus on what the participants in the interaction make relevant and analyse the event 'internally' and technically by grounding analysis in how the participants themselves display their understanding of previous turns in their own responses. Schegloff (1997) proposed that analysis should consider the concerns that participants make relevant in their interaction and an analyst should be able to point to the data to make visible what is happening. Whilst Wetherell agreed that conversation analysis provided a useful discipline, she also suggested that conversation analysis does not offer an adequate answer to the question "why this utterance here" (Wetherell, 1998, 388). "Why that now" being an omnirelevant concern in conversation analysis concerning the monitoring of any 'action' produced in the previous turn of talk and its implications for appropriate responses (Schegloff \& Sacks, 1973,299). Wetherell suggested that Schegloff's focus purely on the transcript was unhelpful and unproductive. Instead, she argued for a 'complete' or 'scholarly analysis' as opposed to Schegloff's 'technical analysis'. To illustrate the need for wider interpretation, Wetherell (1998) drew upon post-modern influences. In comparison to the conversation analyst's focus on talk-in-interaction, post-modern approaches, exemplified by the work of Laclau, Mouffe and Shapiro, make 'discourse' their topic. Here, discourse includes both the discursive and extra-discursive. Although it is argued that meaning and people are in a constant state of 
change, it is recognised that they often emerge as stable forms that last for periods of time. This level of stability is of interest to health psychologists when exploring health behaviours that are entrenched yet hopefully amenable to change and improvement. According to Laclau and Mouffe, individuals both actively make meaning and passively become constituted in the Foucauldian sense by subject positions. Wetherell herself supported the notion of the "highly occasioned and situated nature of subject positions and the importance of accountability rather than 'discourse' per se in fuelling the take up of positions in talk' that a conversation analytic approach would also maintain”(Wetherell, 1998,394). However, she argued for a consideration of the broader, historical 'argumentative texture' that infiltrates our discursive worlds (Laclau, 1993, Laclau \& Mouffe, 1987) and is explored through an analysis of interpretative repertoires. Interpretative repertoires represent relatively coherent ways of talking about things and are part of our shared social understanding (Wetherell, 1998). When these repertoires are brought into play they evoke relevant patterns of detailed arguments which other participants draw upon. Therefore, the immediate preceding turns considered by conversation analysts are only part of the explanation for the meaning in play at that time. The meanings of utterances depend both on local and broader 'discursive systems' in which they are embedded (Wetherell \& Potter, 1987). Wetherell argued that Schegloff's focus lacks the valuable additional contribution of a genealogical study of the broader argumentative threads and the discursive history relevant to a conversation.

The following section introduces research on eating practise, diet and obesity before discussing some illustrative studies from both 'macro' and 'micro' positions. How these differences are played out in practice are discussed below.

\section{Eating practices, diet and obesity}


In recent years we have seen an increase in media representations of various popular but transitory diets (for example Atkins); the perpetration of the ideal of slender, toned bodies; and discussions about rising levels of obesity. In 2000 the World Health Organisation declared that most counties were experiencing an 'obesity epidemic' with overweight and obese individuals at risk for a number of chronic diseases, including diabetes, cardiovascular diseases and cancer (WHO, 2000). Research examining eating practices, diet and obesity is also a central concern for many health psychologists. How people adhere to healthy diets is important for certain illness trajectories, and with the current focus on obesity it is also timely to assess how they can be studied. Physicians who deliver advice about weight-loss and diet often take a moral tone with their patients, placing the responsibility of the overweight on individual ignorance about proper nutrition (Gracia-Arnaiz, 2010). However, as early as 2000 WHO argued that obesity was not simply an individual concern but a problem for the population as a whole and should be treated as such (WHO, 2000). In this paper a range of recent examples of discursive research in the field of eating practices, diet and obesity conducted by researchers from both discursive strands are discussed in order to illustrate analytic concepts and the usefulness of both approaches in highlighting the tension between individual and societal responsibility. The papers were selected on the basis of their usefulness in demonstrating key issues pertinent to each strand. It must, however, be noted that the boundaries between approaches do overlap in places, for example, a focus on accountability is apparent in both 'macro' and 'micro' strands. Thus discussions will also highlight the contribution of this analytic concern as it is used by both strands. 


\section{The contribution of discourse analysis: 'macro' approaches}

In Potter and Wetherell's (1987) seminal book Discourse and Social Psychology the analytic concept of interpretative repertoires was developed (Potter \& Wetherell, 1987) as a useful way to consider how versions of the world are constructed. It is argued that they are the commonplaces (Billig, 1991) of everyday conversation and the building blocks through which people develop accounts and versions of significant events and through which they perform social life. An interpretative repertoire is a recognisable routine of arguments, descriptions and evaluations found in people's talk typically distinguished by familiar clichés, anecdotes and tropes and frequently marked by vivid metaphors. Interpretative repertoires are 'what everyone knows'. Indeed the collectively shared social consensus behind an interpretative repertoire is often so established and familiar that only a fragment of the argumentative chain needs to be formulated in talk to form an adequate basis for the participants to jointly recognise the version of the world that is developing (Wetherell, 2001). Researchers employing this concept find that once interpretative repertoires have been identified it is possible to see that they are drawn upon in different ways (Edley, 2001).

\section{Analysing power and contradiction}

A key analytic focus of 'macro' approaches is to highlight questions around power relations inherent in different discourses or repertoires and whose interests these best serve. The analytic process is typically to examine how discourses or repertoires are deployed and how the individual is positioned, and positions themselves in relation to discourses.

An illustration of this type of discourse work is a study undertaken by Woolhouse, Day, Rickett and Milnes (2011). They examined young women's (focus group) talk around 
food and eating to understand how they negotiated tensions stemming from aspects of heteronormative femininities. They identified three broad discursive patterns in their data: heteronormative femininity as harmful, restrictive and unobtainable; hetero-normative femininity as seductive and hard to resist; and the positioning of participants as normal through the discourse of 'everything in moderation'. Attention to the variation/contradiction of constructions is a central concern for discourse analysis (Potter \& Wetherell, 1987) and highlights how identity is flexible and locally constructed to perform different activities (Edley, 1993). Woolhouse et al demonstrated how this allowed the women to negotiate tensions and contradictions in the way that their participants navigated different, and often contradictory, aspects of hetero-femininity. For example, whilst their participants rejected the hyper-feminine position of "girly girls" who eat salad and engaged in dieting, their discussions simultaneously partially validated Western notions of beauty and the thin ideal (Grogan, 2008). Furthermore, though critical of dieting as shallow they still acknowledged the social stigma attached to 'fatness'.

A focus on how individuals resist dominant discourses is a key contribution of discursive studies and has been a further focus for discursive studies of obesity. Often issues of morality are key concerns for individuals who deviate from culturally sanctioned paths, including 'gay bear' communities. Gough and Flanders (2009) argued that the obesity debate has typically demonised larger people as unhealthy and their (interview) study demonstrated how men discursively managed such categorisations in the context of the obesity debate. Their analysis focused on the positions available for men who identified as 'bears' (where big, and often hairy, gay men are deemed sexually attractive) in line with their identification of three interpretative repertoires: stigmatised bodies; the 'bear' sanctuary; and big as healthy. The men in the study developed 'progressive' narratives detailing previous negative 
body experiences with their more recent acceptance within the bear community in order to situate their former "shamed body" as now desirable. In a similar vein to the women in Woolhouse's study, the men drew upon the notion of choice as a means to reject prejudiced assumptions of passivity and inactivity typically associated with the obese. The policing of appearance from the 'twink society' (twinks being a gay slang term describing a young man with a slender build, and little or no facial/body hair) is worked up as superficial and false in opposition to bears as more ordinary, masculine and 'down to earth'. Distinctions were made between the public perception of what constitutes an ideal body image and private feelings of discomfort with a thin self.

The advantage of this type of research is to highlight how health psychologists might struggle to convince the bear community of the benefits of the BMI measure which was criticised as unrealistic and suggested that health professionals should develop a more nuanced understanding of community norms. These examples illustrate how the concept of interpretative repertoires has been useful in providing a complex, historical picture of ideas about eating practices, diet and obesity and can be applied to other settings (Potter \& Wiggins, 2007). Repertoires provide a way to research the regular descriptive features in data (Wooffitt, 20005) and also studies of identities. Identities are framed within particular repertoires and are open to negotiations of different subject positions that can be taken up and used to make sense of our social worlds at any given point. Attention to the contradictory and situated aspects of identity work of this kind provides a more nuanced understanding of health related behaviour than non-discursive approaches that have a more fixed concept of identity. It allows us to focus on how various discourses set into play a number of positions that women can occupy, negotiate or resist through identity 'work'. 


\section{Accountability}

A second key contribution of both 'macro' and 'micro' strands is an analysis of accountability (Edwards \& Potter, 1992; Potter, 1996). All descriptions perform actions and are open to being discounted as a product of their stake or interest in the version of reality that is being worked up (Potter, 1996). This 'dilemma of stake' is particularly relevant where delicate issues of identity are raised to the fore (Edwards, 1996), as with talk about eating practices and weight. Turns of talk are designed in ways that facilitate the production of fact (where accounts are worked up as 'true'), and accountability (where accounts are oriented towards issues of choice/agency, blame, responsibility). A number of resources are drawn on to work up factual presentations and attend to accountability such as 'stake inoculation' where identities are worked up in a way that wards off any unwanted issues of stake (Potter, 1996). The usefulness of this approach in eating research is exemplified in a study about how individuals recently diagnosed with type 2 diabetes constructed and managed their diet (Peel, Parry, Douglas \& Lawton, 2005). Women in this study presented their diet as an individual concern, something that they have to adapt in order to accommodate the family's eating preferences. In contrast to this, men discussed diet as a family matter which was contingent on their female partner's provision of the 'correct' foods. In accounting for lapses, or cheating behaviour, the participants produced gendered responses which included women drawing upon discourses of responsibility, blame and addiction whereas men did so to a lesser extent.

Peel et al argued that these findings illustrate how gendered discourses are brought into play and women's needs become subordinate to the service of their families. Their work highlights a problem with health professionals who employ rigid categories in relation to diet, such as the 'non-compliant' patient, because the construction of a 'compliant' patient is a 
more complex interactional accomplishment (Peel et al, 2005) and is shaped by local and broader issues and power relations. Furthermore, the pathologising category of the 'noncompliant' patient is treated as adequately descriptive and thus discourages any attention to local and broader issues. Understanding the barriers that patients face in their daily lives could help to determine the best practice in advice about diet.

A further exemplary discourse study investigated the reception of advice on healthy eating. Healthy eating initiatives rely upon advice being taken up by the general population so it is important to understand what messages are effective, or why some advice is ignored. Despite numerous healthy food initiatives, there has been only minimal improvement in the health of the UK population (O'Key \& Hugh-Jones, 2010). To understand more fully issues of scepticism and mistrust of dietary messages, O'Key and Hugh-Jones (2010) argued that it was necessary to consider the meanings that people attribute to them. Their (interview) study considered mother's accounts of dietary practices to examine the ways in which mothers legitimise trust (or mistrust) in healthy eating messages. They found that mistrust was extensively reported but that the rationale varied. For example, they illustrated how discursive devices such as accounts of personal autonomy and reasonableness were employed to justify mistrust. Furthermore, health messages were discredited, and being positioned as an unwitting victim to these was attended to on the grounds that health messages were unreliable and inconsistent. The mothers in the study also positioned themselves as instinctively knowledgeable about their child's needs. Accounts of mistrust justified non adherence to such diet advice in a manner that displayed their actions as wise. The implications for dietary campaigns are that such resistance could be addressed through collaboration with lay and professionals on order to develop transparency and trust. 
In summary, the 'macro' studies outlined in this section demonstrate the contribution of this strand of discursive research as a means of examining the ways in which individuals are situated within specific discourses. As a consequence it is possible to examine the way that notions of individuality are drawn upon as a discursive device in order to account for their decisions as to whether or not they adhere to health advice.

\section{Methodological issues: reflecting on research practices}

The concept of interpretative repertoire has been critiqued by others with regards to the extent that they are reliant on the researcher's frame of reference (see the discussion of Schegloff, 1997 above). Others have also questioned how interpretative repertoires can be reliably identified (Hepburn \& Wiggins, 2007). To remedy the latter point, researchers could address this process more thoroughly in their discussions about the analytic procedure in the method section of research papers.

In addition to this critique about levels of interpretation, discursive psychologists from the Loughborough School differ from most 'macro' discourse researchers in their choice of data collection and the presentation of such data. Interviews are the dominant method of data collection for broad approaches to discourse, and with most other qualitative approaches to health psychology. Indeed, interviews (and focus groups) are often assumed to be the sole source of qualitative data. Therefore, the following discussion of methodological critiques is also applicable to many qualitative health psychologists. The points made in this section also set the scene for the following discussion of the 'micro' discursive psychology strand of research about eating practices, diet and obesity in the next section.

Potter and Hepburn (2005a) outlined some of the problems they associate with 
interview data: data extracts typically ignore the interactional details of talk, for example, by presenting participant responses only and using transcriptions that hide elements of talk which conversation analysts consider to be important features that aid analysis. Consider the fragment of data presented below which is taken from an interview study about obesity with men from weight management programmes ( $\mathrm{J}$ is the participant and $\mathrm{C}$ is the interviewer).

\section{Extract 1: Motivate interview 3}

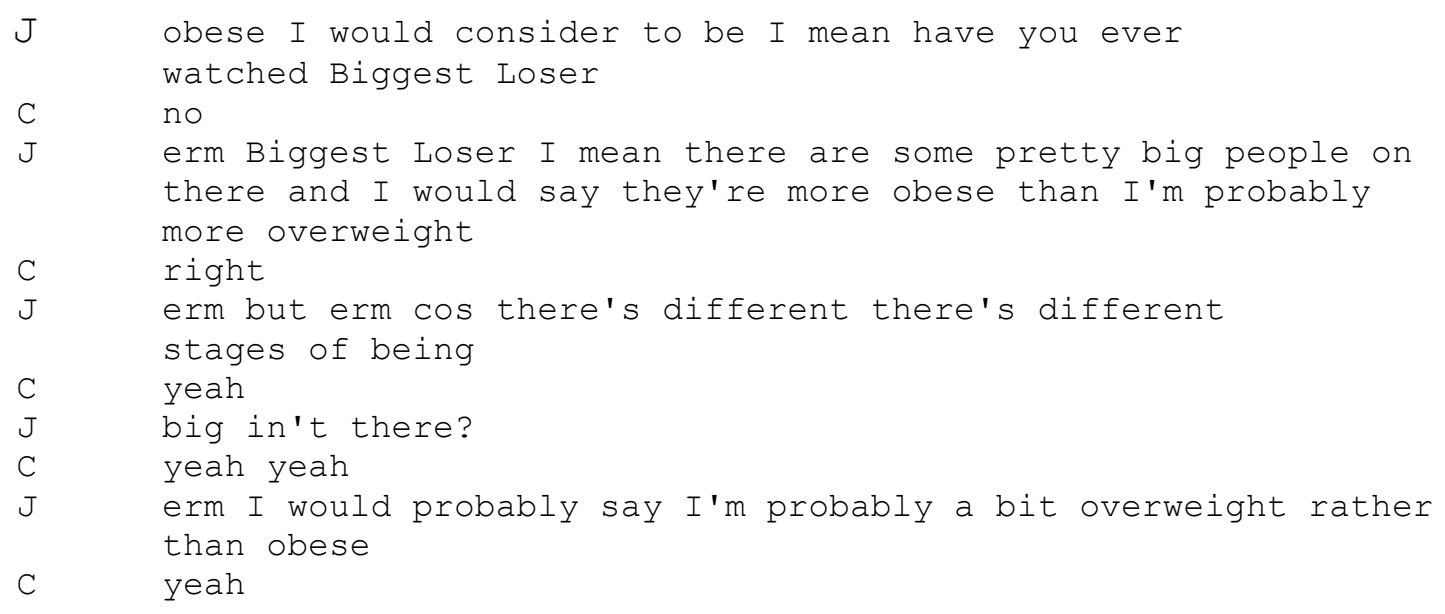

In the extract above the interviewer's question has been deleted so we do not get a sense of the situated nature of this discussion. We can assume that it is in response to some question about the participant's obese category membership but we can glimpse little of how this conversation developed. Analysis of such an excerpt might consider the way that the participant minimises his own obese status. However, if we consider the fragment of data below, a more complex picture emerges.

\section{Extract 2: Motivate interview 3}

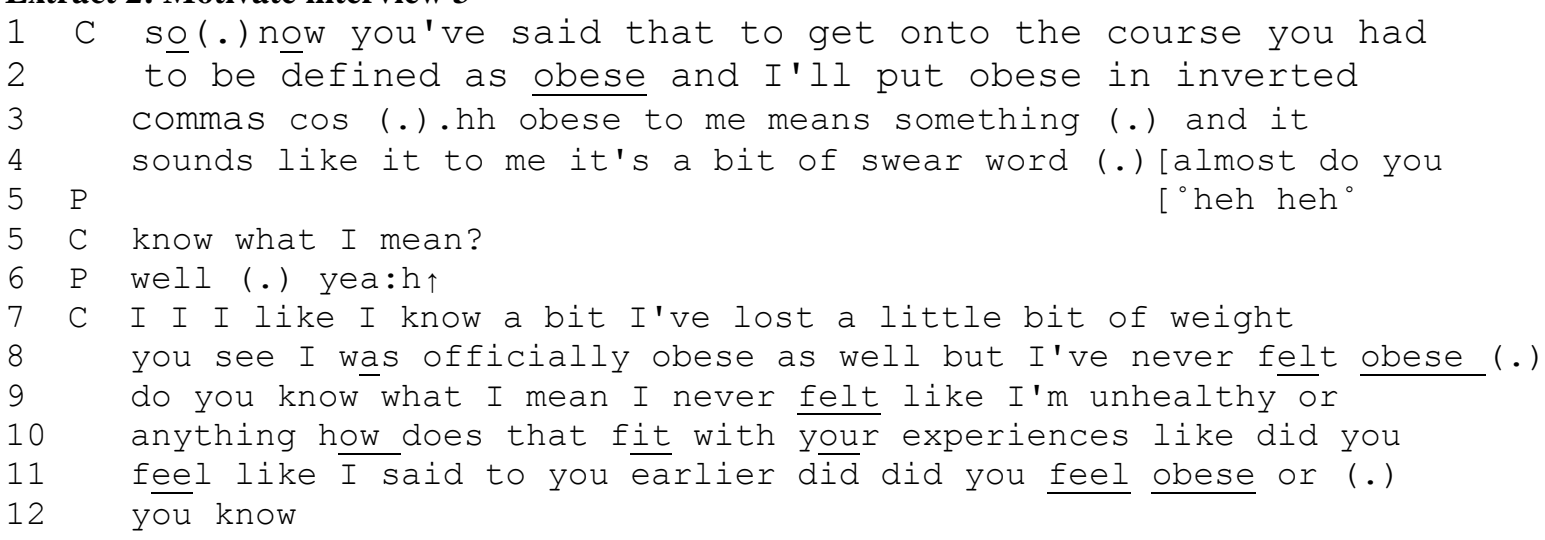




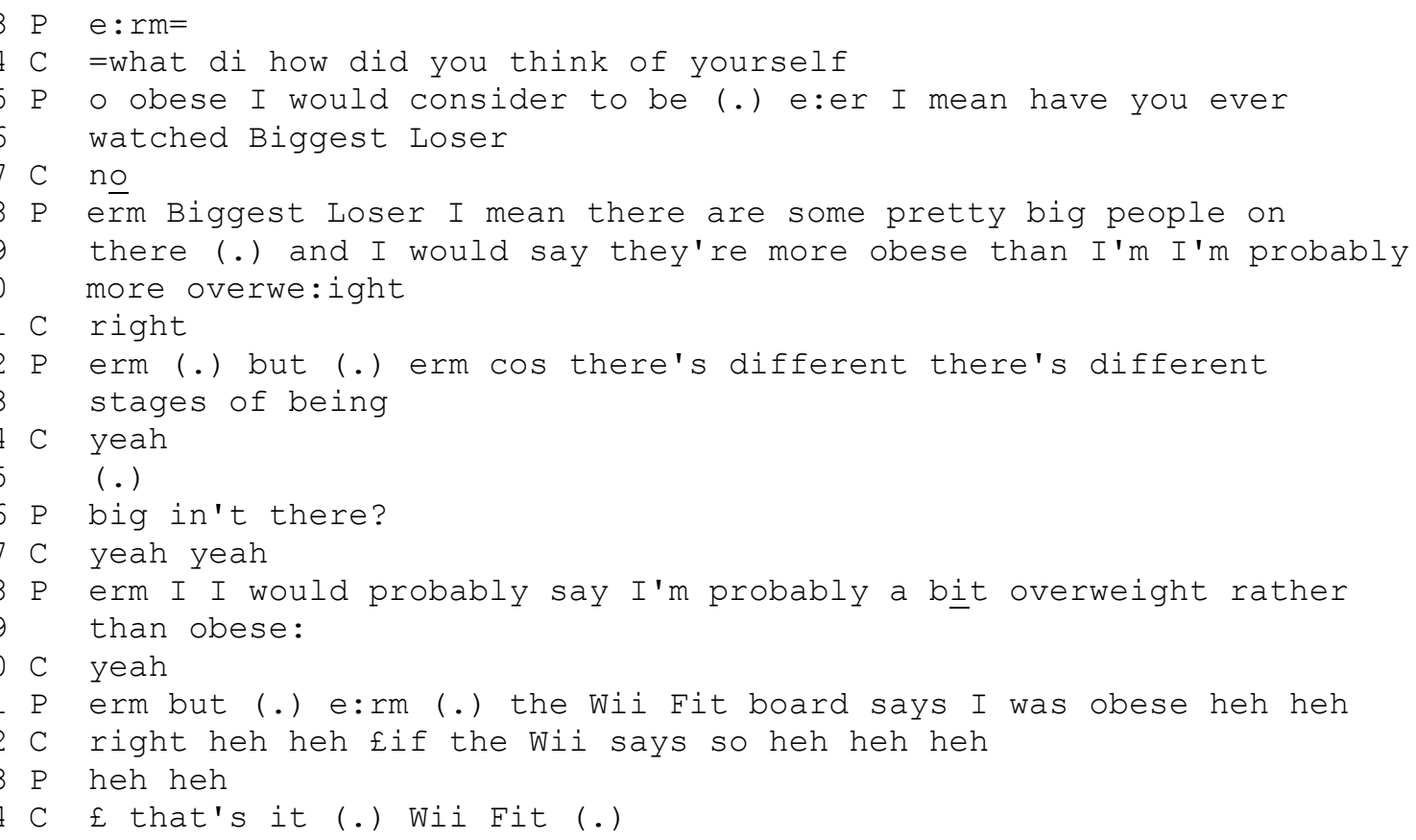

With the inclusion of the interviewer's question, and a more detailed transcription notation (see appendix for details) developed by Gail Jefferson (1985), we can see that this account of obesity is co-constructed between the interlocutors. If we pay attention to the way that sequences evolve we can ground our analyses in the way that participants' treat previous turns, thus enabling us to examine how they understand the ongoing discussion (Schegloff, 2007). A generous interpretation could be that the interviewer is managing the discussion of obesity in a delicate way, or 'doing' rapport, by invoking his own prior obese status.

However, Chris marks out the word obesity as problematic with his use of "I'll put obese in inverted commas" and his following construction of obesity as "a bit of a swear word (.) almost". Chris is orienting to a potential difference of opinion here. The detail in this revised transcript, and the inclusion of the extended discussion, also allows us to notice the minimal uptake of his construction (line 6) by Jack, which is marked with the turn initial delay "well", indicating that this is a disprefered response. Preference organisation describes the patterns of how interlocutors align, or non-align, with the action of a previous utterance (Heritage, 1984; 
Schegloff, 2007). The interviewer continues by detailing his own previous obese status and feelings around that before asking if the participant felt obese. The way that obesity is constructed is thus made relevant to the discussion and this is taken up by the participant who clearly aligns with Chris' stance. Watson's (1997) notion of 'reflexive monitoring' refers to the manner through which categories are sequentially managed, configured, arranged and displayed. The management of categories in talk is a reflexive process which focuses on the interactive and mutually constitutive process of category display and sequential organisation/management. Through a focus on category work in situ we can see how members "tie predicates to devices and categories in terms of the practicality of such connections and the particular here and now activities oriented to in talk" (Housley, 1999, 5.6). Put simply, the argument is that through an examination of how talk unfolds we can examine the way that categories are deployed as they are on display for the researcher to study. The more inclusive extract permits the reader to assess the claims made by the researcher.

Potter and Heburn (2005a) argued that it is hard to disentangle social science agendas from the way that interview research is set up and presented to participants (or other researchers). We see an agenda, or stance, being taken by Chris quite clearly in the extract above. Instead of interview and focus group data discursive psychologists have begun to work with naturalistic materials. The benefits of this move are that: it avoids imposing researcher categories onto the data; it allows us to situate research in everyday settings; thus we can study people's practices in situ rather than reflexively at a distance; it allows the researcher to focus on the issues that are at stake for the participants rather than imposing their own concerns, often resulting in novel topics; and it captures the complexity of often mundane situations (Potter \& Wiggins, 2007, 78-79). 
These insights made by discursive psychologists can be usefully applied to other qualitative health research. The inclusion of interviewer's questions, and a focus on turntaking, allows the reader to assess the validity of our analyses. Let us turn now to consider discursive studies that have analysed naturalistic data in this way.

\section{Discursive psychology: naturalistic data and the influence of conversation analysis}

The focus on accountability and morality seen above are also key interests for discursive researchers working in a fine-grained way. However, rather than relying on anecdotal data the move to naturalistic data allows us to see how such issues are live concerns for individuals' accounting practices in mundane, everyday settings - a key contribution of this second strand of discursive research. As indicated above, drawing upon conversation analysis the analysis is grounded sequentially - people display their understanding of the previous 'turn' of talk (what has just been said) in their subsequent turn (their response and uptake of what was said). Examining such practices in situ allows us to explore the business of talk in settings such as commercial weight management groups (Mycroft, 2008), NHS weight management treatment (Wiggins, 2009), and obesity clinics (Webb, 2009) discussed below.

\section{Morality and social practice}

Successful dieting typically involves following certain requirements such as restricting one's diet and increasing one's fitness in order to maximise weight loss and 'micro' discursive studies have been useful in identifying how issues of morality and accountability are collectively produced and bound up with social practices. Mycroft (2008) considered what female group members made relevant at their 'weigh in' sessions and how 
the group leaders constructed their responses. She found that group leaders and members of the commercial weight loss management group perpetuated moral discourses about 'good' and 'bad' food rather than focusing on healthy eating (Mycroft, 2008). For example, after the delivery of news that a member had gained weight, an account for the increase is offered to the group leader in terms of being 'naughty'. Such displays of non-adherence to the diet make a group member's behavior an accountable issue to the group leader who typically colludes with this construction of restraint from such indulgence. Paradoxically, group leaders and members discussed 'bad' foods as both the sin but also the treat for good eating behavior. An important implication that Mycroft proposed is that health messages about healthy eating in weight management treatment situations is that they should avoid framing food as 'good' or 'bad' and focus instead on changing women's relationship with food and advocating healthy eating.

The normative practice of attributing moral accountability for weight loss can also be seen in the ways that patients manage blame in NHS weight management treatment services. Through an examination of the construction and sequential organization of talk, Wiggins (2009) demonstrated how patients resisted responsibility for weight gain by denying having performed the blameworthy activity (such as resisting blame for eating food that is 'fatty') or locating the blame outside their individual control (for example, invoking medication as a cause for weight gain). Wiggins suggested that whilst patients are drawing upon an individualist concept of weight which reifies the medical model and renders them responsible, their resistance is couched in a way that troubles this model through claims that it does not work even when they adhere to the diet plan. Similarly, a conversation analytic study conducted by Webb (2009) found that patients at an obesity clinic emphasized their own agency by documenting their exercise and improved health when achieving success but 
minimized their agency with mitigating factors, such as difficulty in exercising or reactions to drugs, when they gained weight.

A focus on the sequential organization of talk allows us to see how issues such as blame and accountability to weight management are played out between interlocutors. Interview data allows us to analyse individuals' (and researchers') meaning making about eating practices, diet and obesity but we only get part of the picture, or at least the participants' version of that experience or health encounter of any specific topic under investigation. Naturalistic data incorporates both parties in the health situation, the participant and the health practitioner. This inclusion of the health practitioner is a crucial part of our understanding of issues across a range of health topics including doctor/patient interactions, support groups, and calls to help lines. Through studying such naturalistic interactions we can see more clearly how issues such as compliance and non-compliance are worked up in interactions, and how individuals orient to individual responsibility, both grounded in real life situations.

\section{Compliance as a collective phenomenon}

An analysis of naturalistic data is useful in identifying resistance to the medical model's focus on the individual. To fully understand how the social context of dieting behavior influences the practice of compliance which interview studies such as Peel et al (2005) have outlined, working with naturalistic data highlights the importance of the way that categories such as compliance are employed in patients' everyday life. Studies of naturalistic talk such as online forums allow us to examine the way that patients' manage such practical issues associated with diets. For instance, Veen and te Molder (2010) examined how patients with Celiac disease manage the risk of gluten intake. Following one thread initiated by a 
member whose subject title was "I want to quit" they found that other members rejected this as an option. The original post highlighted that whilst the forum member was able to follow the recommended diet she was 'fed up' with the restrictive nature of it and wanted to quit. Their analysis highlighted the use of 'second stories' (Arminen, 2004; Sacks, 1992) where recipients provide parallel experiences that can perform particular functions such as providing support, offering new insights and offering advice. Veen and te Molder found that responses to the original post typically followed the same format: sharing an experience of a dieting lapse; detailing their own emotional reasons for this lapse; then detailing how this ended badly for them and pushing the value of sticking to the diet along with practical solutions to make it easier to follow. They also noted that members of the forum 'scripted' (see Edwards, 1997) their frustrations with the diet which resulted in portraying this as a routine occurrence for Celiac patients thus negating this as a valid choice for non-compliance. Second stories of confessions to diet lapses and cheating behaviour are also potentially used as a discursive device to normalize this practice yet to also condemn it.

Veen and te Molder's (2010) discursive study illustrates how dietary compliance is, at least in this instance, a collective phenomenon rather than an individual accomplishment (Veen \& te Molder, 2010, 37) and this is supported with another study of bariatric surgery patients. Cranwell and Seymour-Smith (2012) examined posts from a weight loss surgery online support group to explore how members constructed their appetite and weight loss. They found that two concerns were routinely made relevant whilst discussing post-surgery diets: a lack of appetite, and periods of weight stabilization. The analysis demonstrated how members self-regulate, and 'monitor' or 'police' others' weight loss and eating practices. As with Veen at al's (2010) study they noted that second stories were produced as a device to normalize group views and used to correct deviant cases. Members used second stories to 
monitor the intake of appropriate levels of food during the initial post-surgery period where members constructed uncertainty about whether they should eat when their appetite was low. Second stories also helped to induct members into treating periods of weight stabilization periods as routine, constructing such periods as 'blips', in order to urge others to continue with the diet plan. These instances of monitoring were typically in response to solicited advice, in contrast the practice glossed as 'policing' which referred to instances where unsolicited advice was offered to members who deviated from the diet. Their analysis demonstrated how policing was a highly sensitive activity, needing a more delicate delivery than monitoring, in order to 'save-face' on behalf of the recipient. Attention to the sequential aspects of posts allowed an exploration of how monitoring and policing were discursive devices which aided adherence to weight management as a communal rather than an individual responsibility.

\section{Conclusion}

This paper has outlined two strands of discursive research broadly categorised as 'macro' and 'micro'. In doing so the advantage of employing either discourse approach to health psychology has been elucidated. Despite the tensions and debates in the field there are a number of similarities across the two strands. Both are concerned with constructions and descriptions and how they are involved in actions, and both are interested in analysing issues of accountability. As we have seen with the above examples, 'macro' discourse work highlights the cultural context of talk and can demonstrate how individuals are positioned in relation to 'discourses' or 'interpretative repertoires' and how such discourses are accepted, negotiated and resisted. Finer grained perspectives pay attention to the sequential placement of constructions and are best suited to analyse naturalistic data such as any medical interaction or other similar naturalistic contexts like support groups, and calls to NHS health 
lines or the ambulance emergency services.

The collective body of work on eating practices, diet and obesity under discussion has also demonstrated how the issue of individual responsibility is negotiated and resisted by those it directly affects. Research from both strands pays attention to issues of accountability, and shows us something about how the thrust to place individuals at the centre of their own dietary intake is taken on board, negotiated, or resisted. This seems to be a key advantage for health promotion. If we can understand how individuals resist health advice then we are better placed to tailor our health messages to the recipients. Discursive research is able to draw attention to constructions of individualism in a way that attends to the intricacies involved in such accounting practices. Notions of individuality are variously drawn upon by participants as a discursive device in order to account for their decision making regarding adherence to health advice. Furthermore, instances in data that might initially be construed as individual agency, such as the self-reference of "I quit" in Veen and te Molder's (2010) study, is not simply viewed as an instance of individual agency, rather their sequential analysis highlights how dietary compliance is attended to as a communal activity. Discursive research is in a good position to illustrate the point raised by WHO (2000) in relation to obesity, that dieting should be treated as a population based problem and not an individual responsibility. In moving away from a static notion of identity, discursive approaches are able to explore, in some detail, why people resist health advice. Discursive research has illustrated the importance for health promotion to be mindful of how health advice can be viewed as a threat to identity.

A discursive approach could usefully be applied across a whole range of health and illness topics. For those new to discourse work, the prospect of undertaking a discursive study 
can be a bit daunting. 'Macro' approaches have outlined some analytic steps (see Potter \& Wetherell, 1987; Edley, 2001) but finer grained work combines theoretical principles with particular analytic procedures as opposed to following a step by-step guide (Potter \& Hepburn, 2005b). The aim of discursive research is to develop an explanation of the patterns in data, and an analysis of any deviations from that pattern.

The discussion of methodological issues is important for the new discourse researcher to consider but also raises some thoughtful considerations about the use of interview data for the wider population. Attention to the issues raised might help improve the rigour of qualitative research in general. Allowing the reader to view data extracts, which include the interviewer's contributions, can be used to make the interview process, and the process of analysis, more transparent, robust and valid. The reader is provided with an opportunity to more fully assess the research process. Arguments against the use of interview data, however, do create a hierarchy of data that can result in unhelpful comments from reviewers. Interviews are common social encounters and what happens in them is arguably discursively and psychologically interesting (O’Key \& Hughes-Jones, 2010). In comparison to interviews, focus groups are more naturalistic as they include a focus on a range of communicative practices more akin to everyday conversation such as storytelling, disagreements and teasing (Wilkinson, 2008). Indeed, Griffin (2007) illustrates this point in relation to a focus group interview with 'young consumers' with regards to an instance of sharing hand cream that occurred. Griffin's argument was that research interviews allow for the perspectives and agendas of the interviewees as well as the interviewer, highlighting that some assumptions made about the limitations of interview data are over simplistic. 
The Loughborough School have identified one key advantage of working with naturalistic data for health psychologists - we can go straight to the crux of the issues at hand. Interview research allows us to understand the sense making practices of the person who is ill, or on a diet, but if we are able to study the issue at hand in situ then we can incorporate an analysis of the health practitioners' contributions to such health encounters. Studying the actual practices of people 'doing' health and illness in situ is fascinating and enlightening and allows us to examine real life health and illness issues as they unfold. However, studying health topics at a distance can, but not necessarily, desensitise one from the experiences of such individuals. Hearing patients recount their illness narratives in person is a completely different experience to studying medical interactions from a distance. Interviewing can be more visceral and can have a greater impact on our understanding of the condition, although it could result in imposing such feelings onto the analysis. Furthermore, participants' experiences of the research process may be 'therapeutic' and a positive experience. Interview research is typically respectful in acknowledging participants' expertise through experience, whereas having a 'private' medical encounter recorded, without the possibility of any independent input, may feel intrusive.

In summary both strands of discourse research are useful to study health topics and provide a useful addition to qualitative health research. Discourse analysis is a flexible method that can address a range of research questions. Each piece of qualitative health research should ultimately be evaluated in its own terms, regardless of the dominant position in the field as there is scope for all approaches, with no one method providing the definitive answer. One should always seek the most appropriate data for the study at hand and the best method to analyse such data. More important are the rigour of analyses and the validity of analytic claims that are made, whatever the analytic position. The field of discursive research 
is ever changing and this is an exciting time to begin conducting this type of research as new developments unfold.

\section{References}

Arminen, I. (1998). Ogansisation of participation in meetings of Alcholics Anonymous. Issues in Applied Linguistics, 9(2), 59-98.

Billig, M. (1987). Arguing and thinking: A rhetorical approach to social psychology. Cambridge: Cambridge University Press.

Billig, M. (1991). ideology and opinions: studies in rhetorical psychology. London: SAGE.

Billig, M. (1999a) Critical discourse analysis and conversation analysis: an exchange between Michael Billig and Emanuel A. Schegloff, Discourse \& Society, 10(4), 543-558.

Billig, M. (1999b) Conversation analysis and the claims of naivety, Discourse and Society, 10, 572-576.

Buman, E. \& Parker, I. (Eds.)(1993). Discourse analytic research: Repertoires and readings of texts in action. London: Routledge.

Edley, N. (1993). Prince Charles - our flexible friend: accounting for variations in constructions of identity. Text - Interdisciplinary Journal for the Study of Discourse, 13 (3), pp. 397-422.

Edley, N. (2001). Analysing masculinity: interpretatative repertoires, subject positions and ideological dilemmas. In: M. Wetherell, S. Taylor and S.J. Yates (Eds.). Discourse as data: a guide to analysis. London: Sage and the Open University, 2001, pp. 189-228.

Edwards, D. (1997). Discourse and cognition. London: Sage Publications. 
Edwards, D. and Potter, J. (1992). Discursive Psychology. London: Sage.

Harre, R. \& Gillett, G. (1994). The discursive mind. London: Sage.

Gough, B. \& Flanders, G. (2009). Celebrating “obese" bodies: gay "bears" talk about weight, body image and health. International Journal of Men's Health, 8(3) 235-253.

Gracia-Arnaiz, M. (2010). Fat bodies and thin bodies. Cultural, biomedical and market discourses on obesity. Appetite, 55,219-225.

Grogan, S. (2007). Body image: understanding body dissatisfaction in men, women and children. Psychology Press.

Hepburn, A. \& Wiggins, S. (2007). Discursive research: themes and debates. In. A.Hepburn \& S.Willig (Eds). Discursive research in practice: new approaches to psychology and interaction. Cambridge: Cambridge University Press.

Heritage, J. (1984) ‘A Change-of-State Token and Aspects of its Sequential Placement', inJ. M. Atkinson and J. Heritage (eds) Structures of social action:studies in conversation analysis, pp. 299-345. New York: Cambridge University Press.

Hollway, W. (1984). Gender difference and the production of subjectivity. Changing the subject: Psychology, social relations and subjectivity. V.Walkerdine. London, Metuen.

Horton-Salway, M. (2002). Narrative identities and the management of personal accountability in talk about M.E.: a discursive approach to illness narrative. Journal of Health Psychology, Vol. 6 (2) 261-273.

Housley, W. (1999) 'Role as an Interactional Device and Resource in Multidisciplinary Team Meetings'. Sociological Research Online, vol. 4, no. 3, http://www.socresonline.org.uk/4/3/housley.html. 
Jefferson, G. (2004). Glossary of transcript symbols with an introduction. In G.Lerner (ed.). Conversation analysis; studies from the first generation. California; John Benjamins.

Laclau, E. (1993). Politics and the limits of modernity. In T.Docherty (ed.), Postmodernism: A reader. London: Harvestor Wheatsheaf.

Laclau, E., \& Mouffe, C. (1987). Post Marxism without apologies. New Left Review, $166,79-106$.

Fairclough, N. (1995). Critical discourse analysis. London: Longman.

Gilbert, G.N. \& Mulkay, M. (1984). Opening Pandora's box: a sociological analysis of scientists' discourse. Cambridge: Cambridge University Press.

Gracia-Arnaiz, M. (2010). Fat bodies and thin bodies. Cultural, biomedical an market discourses on obesity. Appetite, 55,219-225.

Griffin, C. (2007). Being dead and being there: research interviews, sharing handcream and the preference for analysing 'naturally' occurring data'. Discourse Studies, 9(2), 246-269.

Malson, H. (1998). The thin woman: feminism, post-structuralism and the social psychology of anorexia nervosa. London: Routledge. .

Mycroft, H. (2008). Morality and accountability in a commercial weight management group.Journal of Health Psychology, 13 (8), 1040-1049.

O’Key,V. \& Hughes-Jones, S.(2010). “I don't need anybody to tell me what I should be doing". A discursive analysis of maternal accounts of (mis)trust of ealthy eating information. Appetite, 54, 524-532.

Parker, I. (1992). Discourse dynamics: Critical analysis for individual and social psychology. London: Routledge. 
Peel, E., Parry, O., Douglas, M. \& Lawton, J. (2005). Taking the discuirsive biscuit? A discursive approach to managing diet in Type 2 Diabetes. Journal of Health Psychology, 10(6), 779-791.

Potter, J. (1996). Representing Reality: Discourse Rhetoric and Social Construction. London: Sage.

Potter, J. and Wetherell, M. (1987) Discourse and social psychology: Beyond attitudes and behaviour. London: SAGE.

Potter, J. \& Hepburn, A. (2005a). Qualitative interviews in psychology: problems and possibilities, Qualitative Research in Psychology, 2, pp.281-307.

Potter, J. \& Hepburn, A. (2005b). Discursive psychology as a qualitative approach for analysing interaction in medical settings. Medical Education, 39 (3), pp. 338 - 344.

Potter, J. Wiggins, S. (2007). Discursive psychology. In C. Willig \& W. StaintonRogers (Eds.). The Sage handbook of Qualitative research. London: SAGE.

Sacks, H. (1992). Lectures on conversation (Vol 1\&2). Oxford: Blackwell.

Schegloff, E.A.\& Sacks, H. (1973).

Schegloff, E.A. (1997). Whose text? Whose context? Discourse and Society, 8(2), 165- 187.

Schegloff, E.A. (1998). Reply to Wetherell. Discourse and Society, 9(3), 413-460.

Schegloff, E.A. (1999a). 'Schegloff's texts' as 'Billig's data'.: A critical reply. Discourse and Society, 10(4), 558-572.

Schegloff, E.A. (1999b). Naivete vs sophistication or discipline vs self-indulgence: A rejoinder to Billig. Discourse and Society, 10(4), 577-582. 
Schegloff, E. A. (2007). Sequence Organization in Interaction: A Primer in Conversation Analysis. .Cambridge: Cambridge University Press.

Silverman, D. (1997). Discourses of counseling. London: SAGE.

Veen, M., te Molder, H., Gremmen, B. \& van Woerkum, C. (2010). Quitting is not an option: an analysis of online diet talk between celiac disease patients. Health, 14(1), 23-40.

Watson, D.R. (1997). Some General Reflections of Category and Sequence. In Hester and Eglin Culture in Action: Studies in Membership Categorization Analysis.International Institute for Ethnomethodology and Conversation Analysis and University Press of America, Washington, D.C.

Webb, H. (2009). 'I’ve put weight on cos I've bin inactive, cos I've 'ad me knee done": moral work in the obesity clinic. Sociology of Health \& Illness, 31(6), 854-871.

Wetherell, M. (1998). Positioning and interpretative repertoires. Conversation analysis and post-structuralism in dialogue. Discourse and Society, 9 (3), 387-412.

Wetherell, M.(2001). themes in discourse research: The case of Diana. In M.Wetherell, S. Taylor,, \& S. Yates, S. (Eds.).Discourse, theory and practice: A reader, London: Sage Publications.

Wiggins, S. (2009). Managing blame in NHS management treatment: psychologizing weight and 'obesity'. Journal of Community \& Applied Social Psychology, 19, 347-387.

Wilkinson, S. (2008). Focus groups. In J.Smith (ed) (2 $2^{\text {nd }}$ edition). Qualitative research in psychology: a practical guide to research methods. London: SAGE publications.

Woofitt, R. ( 2005). Conversation analysis and discourse analysis: a comparative and critical introduction. London: Sage. 
Woolhouse, M., Day,K., Rickett, B. \& Milnes, K. (2011).’Cos girls aren’t supposed to eat like pigs are they?" Young women negotiating gendered discursive construcgtions of food and eating. Journal of Health Psychology, 17(1), 46-56.

World Health Organisation (2000) Obesity: preventing and managing the global epidemic. WHO Technical Report series NO. 894. Geneva: Author.

\section{Appendix: Transcription notation}

The form of notation used in the thesis is a simplified version of the transcription notation developed by Gail Jefferson.

- Extended square brackets mark overlap between utterances, e.g.:
A: [men
overlapping utterances
B: [yeah

- An equals sign at the end of a speaker's utterance and at the start of the next utterance indicates the absence of a discernable gap, e.g.:
A: like I said before=
B: =when you mentioned

- Numbers in brackets indicate pause times to the nearest second. A full stop in brackets indicates a pause which is noticeable but too short to measure, e.g.:

A: he meant (2) that he felt (.) ill

- One or more colons indicate an extension of the proceeding vowel sound, e.g.:

B: I was very anxious:s about it

- Underlining indicates that words are uttered with added emphasis and words in capitals are uttered louder than the surrounding text, e.g.:

A: I sent him to see a doctor but he WOULD NOT go

- Laughing is indicated by the word 'heh heh' e.g.:

B: I can't say why heh heh 
- A question mark is used to indicate rising intonation, often when there is a question, e.g.:

A: what did he say that for? 